\title{
The Effects of Polish-Chinese Language Tandem Work at Tertiary Level
}

\author{
Elżbieta Gajek \\ University of Warsaw, Warsaw, Poland
}

\begin{abstract}
The research aims at investigating the role of international collaboration at tertiary educational level to develop linguistic, intercultural, and technical competences in two groups of students from Polish and Chinese universities. The students communicated in pairs orally via Tencent Instant Messenger (Tencent QQ) exchanging views and opinions on topics prescribed by their teachers. The theoretical model is based on Vygotsky's Social Constructivism and the concept of tandem work via technology. The results of the case study show students' engagement in the task and their positive attitudes towards collaborative work between the two groups of students from the geographically distant universities. The results may be used for establishing formal collaboration projects among academic institutions.
\end{abstract}

Keywords: e-learning, language learning, tertiary education, tandem, project, intercultural competence

\section{Introduction}

The main aim of language learning is to communicate with other people. With the growing number of non-native speakers of English, students need to be prepared for coping not only with various native and non-native accents, but also with the intercultural aspects of the interaction among non-native speakers. Particularly, they need to be sensitive of inferences rooted in native languages of the interlocutors. The rapid development of technology allows for human communication at tertiary education via e-learning devices, such as audio and video messengers, despite the geographical distance.

The idea of building an educational environment to provide interactions between students of different languages was introduced at the beginning of the 19th century. It was called a mutual method. To native speakers of different languages, they communicated in order to learn languages. Each native speaker of one language wanted to learn the language of the partner. So they worked in two languages changing the roles of a teacher and a learner. Then, in the 1960s, the concept was applied into tandem work. Pairs of students learnt in tandems exchanging handwritten letters. In a pair, each student was a native speaker of the language and the second one learnt, e.g., a student from Great Britain who wanted to learn German worked with a student from Germany who wanted to learn English. They used two languages in communication. When Information and Communication Technologies (ICTs), and especially the Internet was introduced into education, students exchange via e-mails under the scheme of tandem was immediately applied (Ayoun, 1996; Levy, 1997, pp. 170-172). At the beginning, asynchronous communication via e-mails was investigated (Warschauer, 1996;

Elżbieta Gajek, Ph.D., assistant professor, Institute of Applied Linguistics, University of Warsaw. 
Gajek, 2000). Following the development of speech transmission, tandems in which students communicated orally were introduced into teaching and learning of foreing languages, and more emphases were put on intercultural aspects of students' communication (O’Dowd, 2006).

Vygotskyan model of social constructivism (Wertsch, 1985) at tertiary level provides ground for students to build own resources contrary to usual acquistion of external knowledge, to develop own strategies of scientific thinking, and to justify opinions, as well as to develop critical thinking (Hessen, 1977). Within the constructivist didactics, Klus-Stańska (2010) stressed the role of a learning environment in which students have to solve problems facing a cognitive conflict and to negotiate meaning to verify previous prespectives and concepts. Thus, learning is not the acquisition of external concepts, but building own perspective based on socially negotiated meanings. Klus-Stańska (2010) claimed that cognitive procedures remain in students' mind longer than the results of their activities as learning to a great extent, which is subconscious. Thus, neither students nor teachers can fully control the process of learning. What is more, planning teaching is understdood as creating occasions for learning with the holistic view of effects even if the partial results are not known or it is impossible to predict them. According to Crook (1994), cross-cultural collaboration "makes sense of 'learning' by reference to the social structure of activity". Chapelle (2000) also perceived the Vygotskyan concepts as grounds for collaborative Net-based language teaching and learning.

\section{Methodology}

\section{Aims of the Study}

The resarch aims at demonstrating the integration of a tele-collaboration project into the academic curriculum and checking its effects. The specific objectives were to develop: (a) linguistic competence in speech and writing; (b) intercultural competence; and (c) computer literacy through the use of e-learning tools in the students.

\section{Subjects and Research Procedure}

The 97 participants of the study came from two institutions: Institute of Applied Linguistics, University of Warsaw (48 students) and School of English and International Studies, University of International Business and Economics in Bejing (49 students). The participants' task was to talk in Chinese-Polish tandems one hour per week. They got 10 topics for a start prepared by the Chinese partner and accepted by the Polish teacher. The themes for discussion are presented below, covering selected cultural issues. On the one hand, the topics were undertaken in typical language courses, so the students were familiar with them. On the other hand, the topics reflected the basic areas of the students' life and experience, which enhanced the sense of learning and increased motivation. At the initial intercultural training session, the Polish students were instructed to search for universal human values and to identify similarities rather than differences. The following topics were suggested:

Hobbies: Story reading, mountain climbing, bar drinking, movie watching, majiang playing, sight seeing, paper cutting, gardening, or whatever;

Campus life: Location, size of the university, college rankings, fields of study, courses taken each semester, students' workload, student organizations, student activities, and parties;

Holidays: Major Chinese/Polish holidays, what people do during the holidays, and special or historical meanings of some of the traditional holidays, such as the Spring Festival, Mid-Autumn Festival, Halloween, 
Independence Day, Valentine's Day, Qixi Day (or the Chinese Valentine's Day), Qingming Day (Ching Ming Day), etc.;

Cuisine: Major cuisines in China and Poland, well-known local snacks in your hometown and in the place where you go to college, your favorite snacks in the local area, and advantages and disadvantages of the local snacks;

Education: Compulsory education, costs K-12 education (e.g., fees for luncheons, textbooks, school uniforms, activities, etc.), competiveness for college admission (e.g., college entrance exams, high school grade point average (GPA), high school students' workload, extra hours for evening or weekend cram classes, etc.), higher education and employment prospects, relationship between what is specialized at college and choice of jobs, and level of education and job-seeking success;

Travel: Places of historical interest in your country/region, places you want to visit most (reasons, etc.), and your preferred transportation vehicle for travel (e.g., reasons, etc.);

Leisure activities: Going window shopping, visiting museums, playing Taiji in parks, workouts by going to fitness clubs, going to the movies, singing in a chorus, and others;

Foreign language learning: Purposes of learning a foreign language, importance of learning a foreign language, foreign language courses offered by the university, ways of learning in language classes, ways of learning outside of classes, successful experiences of learning a foreign language;

Business: Business etiquette (attire, dining, meeting, etc.), business travel (e.g., Do you like a job involving lots of business traveling? etc.), business gifts, corporate bribes, business success (e.g., What are some of the crucial things that can help achieve business success when communicating with Chinese and Polish?), and other topics that may interest you;

Employment: Your ideal profession (e.g., What and why is it?), your education and profession (e.g., How has your education built a strong foundation for your ideal profession?), current employment situations in your country, preparedness (e.g., What will you do if you fail to get a job in your ideal profession? Will you rely on social welfare? Why or why not?) (Zhang, 2011).

The students were informed that they could make use of the themes, but they are not restricted to them. They could also choose other topics depending on mutual interest. The students used Tencent Instant Messenger (Tencent QQ) with the interface in English. It serves for video and audio communication and it has an English-Chinese and Chinese-English dictionary.

\section{Research Instruments}

The Polish students wrote a log entry of 4-5 sentences after each online meeting with the partner in tandem. The focus of the entry was not to summerize the content, because the topic was prescribed for each talk, but to present what they have learnt, what was new, and how they negotiated meaning of various cultural phenomena. At the end of the project, the students filled in two questionnaires, one focused on learning strategies, the other one focused on the overall impact of the tele-collaboration project.

\section{Results}

According to the requirements, $40 \%$ of the students spent 10 hours talking with their partners, $15.5 \%$ spent 11-16 hours, $26.5 \%$ spent 16-20 hours, and 9\% spent more than 21 hours. As the students could communictate through various communication tools, $50 \%$ used audio tools, $31 \%$ video, $20 \%$ chat, $18 \%$ e-mail, and $49 \%$ of them did not use e-mail at all. They switched into e-mail or chat only if the quality of audio or video 
transmission was so poor that communication was not possible.

The Polish students were satisfied with the linguistic results of the project, in particular with the possibillity to speak English regularly and overcome barriers in speaking. They appreciated the fact that they could speak English outside the university. The students reported that their Chinese partners were also satisfied with the opportunity to speak in English. They revised and developed specific vocabulary depending on the interlocutors' interests. One student entered the project with a stressful feeling that speaking is her weakest skill and finally reported friendly and nice conversations. Some of them revised language of everyday natural chatting. Both groups positively commented on the chance to speak with a non-native interlocutor. They appreciated either high fluency in English on both sides or the need to adopt the native accent of the partner, which they treated as a practice in global English. Even if they had to limit the use of coloqial phrases because of the partner's low proficiency of English, they perceived this as a vital linguistc-intercultural experience. In one case, a student also appreciated the high level of understanding of the linguisic barriers showed by her Chinese partner. Some of the students who had been learning Chinese tested their skills in this language. They also learnt some phrases in Chinese. The Chinese partner was a tutor to taught her/his Polish partner new words and how to write in Chinese when they chatted. In the final questionnaire, linguistic benefits were emphasised by almost all participants. The majority of them did not feel nervous at all; on the contrary, they felt excited and curious. Some mentioned a little anxiety at the very beginning caused by: (a) the conversation with an unknown person; (b) being not sure whether their English was perfect; and (c) the potential problems with technology. They reported that the initial nervousness disappeared quickly.

Most of them did not think about developing strategies in communication. If any of the partner tandem could not understand a word said by the other side, he/she either typed the word or send a relevant picture, e.g., with photos of dishes. A few of them even revised vocabulary for the topics which made them more confident and responsive during the conversation. What is more, most of them reported an increase in confidence in speaking English, particularly those who had felt a bit nervous at the beginning. They all realised that cultural differences were not the obstacles in communication, because despite the differences, they were alike. They discovered that in a common language, curiosity, courtesy, mutual positive attitude, and lack of prejudices were the prerequisites for successful communication.

The students emphasized the increase of their intercultural competence. As many of the students did not have a chance to speak with a Chinese person before, they could verify stereotypes. They liked the "exotic" contact with a culture new to them. Many of them changed the view of China as a country producing mass commercial products but as a place where people have similar dreams and desires — with different opportunities. As a result of that change in the vision of the Chinese culture, one of them even started thinking of a two-month apprenticeship in China.

The students also reported an increase in their interests in the Chinese culture. For them, chatting was more interesting than reading newspapers and online texts because of the personal interactions through audio and video. They appreciated vivid and proximate contact with the Chinese tandem partners and their culture. They could look at the partners' culture through the partners' eyes and share their own cultural values with their partners. Some of them had not known much about the Chinese culture before, so they learnt a lot when communicating with their partners. And those who had been interested in Chinese culture, architecture, and cuisine found a guide who could explain the meaning. The students noticed both the distance between the cultures and similarities which made them more sensitive and responsible in intercultural contacts. They were able to "wear their partners' 
shoes" and took their perspective in looking on the same cultural phenomenon.

The students appreciated the list of topics which served very well for the start. The topics did not limit them but encouraged them to ask questions within the natural flow of the conversation. As the topics partially overlapped, the students were encouraged to select other themes for their mutual interests.

The students also reported problems with technology. These were the main barriers reported by the students. Low quality of the Internet connection in student hostels in Warsaw and Beijng was the main obstacle in audio and video commnication. The connection was disturbed when the Net was overloaded, especially on Fridays. The time distance was not convenient because they could not talk at daytime because of the university duties, but either early in the mornings or late at nights.

They also reported different levels of engagement in the activity, in one tandem, the Chinese partner made the conversation very long, in another tandem, the Polish parener seemed to be more interested in the Chinese culture. Both sides complained when the dates agreed were suddenly cancelled by the partner.

In the evaluation of questionnaire, the students declared that they would want to participate in such projects - as the task was interesting, pleasurable, and advantageous. However, they would prefer smaller time distance. Some tandems reported that their would continue the tasks as they had so many questions to ask, topics to discuss, and details to explain. In fact, a year later, some of the tandem partners talked regularly at least once a month.

To sum up the students' results, they met peers of their ages and at similar academic situation. They were able to exchange plans, dreams, worries, and descriptions of lifestyle. They developed critical thinking, in particular when they got inconsistent information from various partners. In this way, they learnt how to differenciate subjective opinions from general ones. As young people, they did not have much experience in personal contacts with foreigners. Thus, the project was an occasion to overcome communication barriers and anxiety, which were more psychological than linguistic as the Polish students were fluent speakers of English. They discovered the culture in an ethnographic manner and in an online environment by interpreting messages they got. Their intercultural competence as an ethnographic investigator was learnt-by-doing. They were able to negotiate meaning and ask for clarification. Finally, they realized that they participated in a virtual tour at a distant university with students of the university as guides. They learnt that the knowledge they got was not comprehensive, but instead, they got insights into their peer-students' lifestyle and private life, which are rarely included in any commentary of general nature.

Teacher's qualitative evaluation was based on focus group's interviews and content analysis of the log entries. Tandem work was smoothly incorporated into the syllabus of the academic course, which aimed at developing linguistic, intercultural, and technical skills in students. The students were personally involved in communication which made sense of learning. The students experienced authentic oral communication between non-native speakers of English. They also developed plurilingual competence playing with the languages when Chinese students repeated words in Polish and Polish students repeated tones in Chinese words. They had a chance to practice intercultural understanding in the experiential mode of learning. They became sensitive to cultural similarities and differences and realised the importance of responsibility in intercultural communication. The technology was not mentioned or even noticed if it worked properly. If technical interruptions did not disturb the conversation, technology was invisible, which illustrates the normalization stage of technology adoption (Bax, 2003). However, when the technological problems hindered communication, the students learnt how to overcome them by either changing the tool (e.g., QQ into Skype) or the channel of communication (e.g., 
from video and audio into chat or e-mail).

A vital professional observation on the teacher's side was the investigation of the effects of constuctivist didactics. Working in tandems illustrates the principles of constructivist approach to learning and teaching. The students had to solve linguistic, intercultural, and technical problems. They negotiated meaning to verify previous perspectives and concepts, because the teacher prepared the project as an occasion for learning with the holistic view of effects. However, the partial results had not been known. What is more, nobody could predict the partial results. Within the theory applied, it is claimed that cognitive procedures remain in the students' minds longer than the results of their activities. This is the long-term effect of the project. Even if the effect is not measurable nowadays, it must be estimated and introduced at the tertiary level of education.

\section{Conclusion}

The case study presents the effects of the Polish-Chinese students' tandem work, which can be incorporated into a regular academic course. The project was a success from both the teachers' and the students' perspectives. For the teachers, the investigation shows that constuctivist didactics applied at tertiary level brings benefits in terms of linguistic, intercultural, and technical competences-Which were the aims of the course. For the students, it was a learning experience, which provided them with various conversational skills in an intercultural environment. What is more, by practicing computer-mediated communication, they are better prepared for learning and professional purposes. Although the case study does not allow for general statements, the results indicate stages in organizing such collaborative projects among students and show the benefits and potential barriers. Thus, the findings may serve as signposts for formal collaboration among universities.

\section{References}

Ayoun, D. (1996). Write from the start! E-mail for beginning French students. In M. Warschauer (Ed.), Virtual connections:

Online activities and projects for networking language learners (pp. 41-43). Honolulu, H.I.: University of Hawaii Second Language Teaching and Curriculum Center.

Bax, S. (2003). CALL—Past, present and future. System, 31(1), 13-28.

Chapelle, A. A. (2000). Is networked-badsed learning CALL? In M. Warschauer, \& R. Kern (Eds.), Network-based teaching: Concepts and practice (pp. 204-228). Cambridge, U.K.: Cambridge University Press.

Crook, C. (1994). Computers and the collaborative experience of learning. London, U.K.: Roultedge.

Gajek, E. (2000). E-mail for English. Network, 3(1), 9-12.

Hessen, S. (1997). Podstawy pedagogiki. I: S. Hessen. Dzieła wybrane T1. Warszawa: Wydawnictwo Akademickie "Żak".

Klus-Stańska, D. (2010). Dydaktyka wobec chaosu pojęć i zadań. Warszawa: Wydawnictwo Akademickie "Żak".

Lewis, T., \& Walker, L. (Eds.). (2003). Autonomous language learning in tandem. Sheffield, U.K.: Academy Electronic Publications.

Levy, M. (1997). Computer-assisted language learning: Context and conceptualization. Oxford, U.K.: Oxford University Press.

O'Dowd, R. (2006). Telecollaboration and the development of intercultural communicative competence. München: Langenscheidt-Longman.

Warschauer, M. (Ed.). (1996). Virtual connections: Online activities and projects for networking language learners. Honolulu, H.I.: University of Hawaii Second Language Teaching and Curriculum Center.

Warschauer, M., \& Kern, R. (2000). Network-based teaching: Concepts and practice. Cambridge, U.K.: Cambridge University Press.

Wertsch, J. V. (1985). Vygotsky and the social formation of the mind. Cambridge, M.A.: Harvard Univeristy Press.

Zhang, H. (2011). Topics for discussions (Unpublished internal project materials). 